Original Research Paper

\title{
Pelatihan Wisata Edukasi Interpretasi Flora pada Kelompok Sadar Wisata di Jalur Pendakian Propok Lombok Timur
}

\author{
I Gde Mertha' ${ }^{1}$, Agil Al Idrus ${ }^{1}$, Abdul Muhyi Abidin ${ }^{2}$, Lale Yaqutunnafis ${ }^{3}$, Baiq Salkiah ${ }^{3}$ \\ ${ }^{1}$ Biology Education, University of Mataramy, Indonesia; \\ ${ }^{2}$ English Education, University of Nahdlathul Wathan, Indonesia; \\ ${ }^{3}$ Economic Education, University of Nahdlathul Wathan, Indonesia;
}

https://doi.org/10.29303/jpmpi.v3i2.1002

Sitasi: Mertha, I. G., Idrus, A. A., Abidin, A. M., Yaqutunnafis, L \& Salkiah, B. (2021). Pelatihan Wisata Edukasi Interpretasi Flora pada Kelompok Sadar Wisata di Jalur Pendakian Propok Lombok Timur. Jurnal Pengabdian Magister Pendidikan IPA, 4(4)

\section{Article history \\ Received: 15 September 2021 \\ Revised: 20 September 2021 \\ Accepted: 27 September 2021 \\ *Corresponding Author: I Gde \\ Mertha, Biology Education, \\ University of Mataramy, \\ Indonesia; \\ Email: \\ gdemertha19@gmail.com}

\begin{abstract}
The hiking trail of Propok in the National Park of Rinjani mountain is very potential for educational tourism activities based on flora biodiversity. In the context of educational tourism, the Tourism Awareness Group (Pokdarwis) which plays a role in managing the Propok route needs to receive training on flora interpretation. This service aimed to provide an assistance in the practice of interpreting tree flora to tour guides from the Tourism Awareness Group on the Propok hiking trail. The method used was training and performance in the form of practical assistance combined with lecture, discussion, demonstration and question and answer. The training activities that had been carried out were practical assistance for tree flora interpretation activities and independent practice of flora interpretation, which was followed by trials on students in the field. The conclusion of this service reveal that (1) The flora interpretation training received a positive response from the training participants and got a very valuable experiences to improve their skills in educational tourism activities, (2) The great enthusiasm of the trainees in carrying out the practice of flora interpretation greatly supports the success of this training activity, and (3) The tree flora interpretation activity for students on the Propok hiking trail was well received, considered very useful and enjoyable. Thus, educational tourism activities can add to the tourist attraction on the Propok hiking trail.
\end{abstract}

Keywords: Tourism; Education; Interpretation; Flora

Wisata edukasi atau wisata pendidikan tidak hanya bertujuan untuk menghibur, namun juga menjadi wahana pembelajaran bagi wisatawan, baik pelajar dan orang dewasa. Konsep wisata edukasi direncanakan atau dirancang untuk memenuhi kapasitas yang spesifik, yaitu ilmu pengetahuan para pelajar. Program ini memadukan muatan pendidikan dengan unsur kegiatan wisata didalmnya. Berwisata sambil belajar menjadi momen menyenangkan dan tidak membosankan bagi anak. Karena itu wisata pendidikan diharapkan menjadi sarana 
pelajar untuk lebih bersemangat dalam belajar, menyederhanakan proses pembelajaran, dan praktek langsung ilmu pengetahuan di lapangan.

Dalam pelaksanaan kegiatan wisata edukasi diperlukan kegiatan interpretasi yang menghubungkan pengunjung dengan objek sumberdaya yang ada. Interpretasi menurut Eva (2011) suatu seni dalam menjelaskan keadaan lingkungan (flora, fauna, proses geologis, proses biotik dan abiotik yang terjadi) oleh pengelola kawasan kepada pengunjung yang datang ke lingkungan tersebut sehingga dapat memberikan inovasi dan menggugah pemikiran untuk mengetahui, menyadari, mendidik dan bila memungkinkan menarik minat pengunjung untuk ikut menjaga lingkungan tersebut ataupun mempelajarinya lebih lanjut. Berdasarkan metodenya, interpretasi dibagi menjadi dua (Endriesta, 2019), yaitu personal dan non-personal. Dalam penyampaian pesan, interpretasi personal membutuhkan seorang fasilitator yang disebut interpreter, sedangkan non-personal melalui media.

Kawasan wisata jalur pendakian Propok merupakan salah satu bagian Taman Nasional Gunung Rinjani yang memiliki tipe ekosistem cukup lengkap, baik hutan hujan tropis dan padang savana. Dibukanya jalur pendakian menuju Savana Propok bagi masyarakat umum menjadikannya salah satu tempat wisata yang memiliki keunikan tersendiri. Namun tidak hanya sampai disitu, masih banyak potensi wisata yang dapat dikembangkan lebih lanjut terutama di jalur pendakian dalam hutan hujan tropis. Jalur tersebut sangat kaya dengan keanekaragaman flora mencakup jenis-jenis khas dengan berbagai variasi morfologi yang potensial sebagai sumber belajar.

Hasil survey tahun 2020 menunjukkan bahwa jalur pendakian dalam hutan Propok memiliki keanekaragaman jenis pohon cukup tinggi. Semua jenis pohon yang terdapat di jalur pendakian tersebut, baik yang berada pada topografi mendatar dan topografi menanjak telah memiliki label papan interpretasi yang berisi informasi nama ilmiah (dalam bahasa
Latin) dan nama lokal (dalam bahasa Sasak). Selain label interpretasi nama tumbuhan, beberapa jenis pohon dilengkapi pula dengan informasi etnobotani. Keberadaan keanekaragaman flora di jalur pendakian yang cukup strategis ini (Mertha et.al., 2020) diharapkan mampu menjadi lokasi pusat penelitian, serta bahan belajar dan pembelajaran, yang dapat meningkatkan kompetensi dan wawasan pembelajar dalam upaya peningkatan kualitas pendidikan, sekaligus menjadi tujuan wisata edukasi berbasis ilmu pengetahuan (science) di Pulau Lombok.

Keterlibatan masyarakat lokal dalam pengelolaan kegiatan wisata kawasan Propok cukup besar. Perkumpulan masyarakat pemerhati wisata yaitu Kelompok Sadar Wisata (Pokdarwis) Desa Bebidas, Lombok Timur, menunjukkan partisipasi aktif dalam pengaturan kegiatan wisata alam di pegunungan ini. Kelompok Sadar Wisata turut merencanakan, mendiskusikan dan membuat strategi dalam pengelolaan pariwisata kawasan Propok, termasuk rencana penyusunan konsep wisata inovasi yang sesuai.

Selain berpartisipasi dalam perencanaan program, anggota Kelompok Sadar Wisata banyak yang aktif sebagai pemanduan wisata, Akan tetapi, kapasitas sumberdaya yang dimiliki umumnya masih terbatas sebagai pemandu wisata adventure (pendakian). Sebagian besar pemandu belum bersertifikat, karena belum pernah mengikuti pelatihan, baik pelatihan pemandu adventure dan pelatihan pemandu wisata minat khusus yang lain, misalnya interpretasi flora. Kemampuan para pemandu wisata dalam bidang interpretasi keanekaragaman hayati flora ini masih sangat minim.

Interpretasi keanekaragamn flora di kawasan jalur pendakian Propok dalam rangka wisata edukasi harus ditunjang petugas interpreter yang kompeten. Seorang interpreter menurut Eva (2011) diharapkan menguasai antara lain jalur interpetasi, materi interpretasi, objek interpretasi, dan skenario cerita. Dalam 
pencapaian target tesebut, maka agar dapat menjadi interpreter flora yang berkualifikasi baik, seorang pemandu wisata perlu dibekali penguasaan ilmu botani lapangan dan teknik penyajiannya kepada pengunjung.

Mengingat sumberdaya tumbuhan sumber belajar cukup lengkap di kawasan hutan Propok, maka wisata edukasi berbasis keanekaragaman flora dapat menjadi industri pariwisata yang potensial untuk dikembangkan. Kegiatan inovasi pariwisata ini diharapkan dapat meningkatkan kunjungan wisata dan membuka lapangan pekerjaan baru untuk meningkatkan perekonomian masyarakat. Oleh sebab itu dalam rangka pengembangan wisata edukasi di jalur pendakian tersebut, telah dilakukan pelatihan interpretasi flora terhadap Kelompok Sadar Wisata (Pokdarwis) yang mengelola objek wisata Propok.

\section{Metode}

Pelatihan dilaksanakan selama sembilan hari dalam lima tahapan seperti ditampilkan pada Tabel 1 .

Tabel 1. Tahapan kegiatan pelatihan interpetasi flora di jalur pendakian Propok Lombok Timur.

\begin{tabular}{ll}
\hline Tahap & Uraian Kegiatan \\
\hline Persiapan & Tim pengabdian menyiapkan \\
& semua keperluan untuk kegiatan \\
& pelatihan, antara lain kunci \\
& determinasi, booklet, dan \\
& deskripsi flora pohon.
\end{tabular}

Sosialisasi Tim pengabdian menyampaikan materi tentang wisata edukasi dan teknik interpretasi flora, serta gambaran pelaksanaan pelatihan. Tahapan kegiatan ini dilakukan dengan metode ceramah, diskusi, demonstrasi, Focus Group Discusions (FGD) dan tanya jawab.

Pendampingan Pada tahapan ini dilakukan praktek latihan interpretasi pohon yang telah memiliki label interpretasi dengan bimbingan dari tim pengabdian. Pada kegiatan ini dilakukan juga pengenalan pohon yang belum memiliki label berdasarkan kunci determinasi dan foto-foto pohon yang telah dilengkapi deskripsi.

Praktek mandiri Pada kegiatan praktek ini setiap peserta diberi tugas melakukan interpetasi pohon secara mandiri berdasarkan skenario cerita yang telah disusun. Tugas lain yang diberikan adalah identifikasi pohon mengacu pada panduan.

Monev Untuk saran dan tindak lanjut kegiatan, tim pengabdian dan peserta pelatihan melakukan refleksi membahas kendala atau persoalan yang dihadapi selama pelatihan dan berdiskusi tentang tingkat keberhasilan program.

\section{Hasil dan Pembahasan}

Berdasarkan hasil penyampaian materi dan praktek interpretasi keanekaragaman flora, para peserta dapat mengerti prinsip dasar wisata edukasi (edutourism). Konsep yang telah dipahami peserta terkait wisata edukasi interpretasi flora, yaitu wisata edukasi sebagai sebuah pogram yang memadukan antara wisata dengan unsur pendidikan didalamnya yang didisain untuk memenuhi kapasitas ilmu pengetahuan bagi pelajar, kriteria wisata edukasi untuk pelajar dan orang dewasa, objek wisata edukasi, kualifikasi petugas interpreter, dan pengalaman berharga sebagai interpreter pemula dalam interpretasi flora di kawasan Propok.

\section{Penyusunan program interpretasi}

Program interpretasi yang disusun untuk kegiatan wisata pendidikan ini bertujuan untuk menghubungkan suberdaya flora dengan pengunjung pada jalur pendakian dalam hutan hujan tropis. Pemanduan/ interpretasi dimulai dari pintu masuk sampai batas hutan dengan padang savana. Semua jenis pohon yang 
berada pada jalur tesebut menjadi objek interpretasi.

Dalam penyusunan program interpretasi ada beberapa tahapan yang harus dilaksanakan yaitu (Eva, 2019): (1) menentukan tema dan tujuan pembuatan program; (2) inventarisasi sumberdaya yang terdapat dalam lokasi; (3) analisa data; (4) sintesa; (5) uji coba; (6) evaluasi. Contoh program interpretasi flora pohon hasil diskusi dengan peserta pelatihan untuk jalur pendakian pada kawasan hutan tropis Propok disajikan pada Tabel 2.

Tabel 2. Contoh program interpretasi flora pohon di kawasan hutan Propok, Taman Nasional Gunung Rinjani.

Tema : Keluarga pepohonan.

Tujuan: Mengenal ciri taksonomi suku terpilih.

\begin{tabular}{|c|c|c|}
\hline No. & Program interpretasi & Materi /praktek disajikan \\
\hline 1. & $\begin{array}{l}\text { Pengenalan suku } \\
\text { Oleaceae (melati- } \\
\text { melatian) }\end{array}$ & $\begin{array}{ll}\text { - } & \text { Ciri-ciri suku Oleaceae } \\
\text { - } & \text { Pengamatan pohon } \\
& \text { Rike (Olea paniculata) } \\
\text { - } & \text { Booklet pohon Rike } \\
& \text { (Olea paniculata) } \\
\text { - } & \text { Apa ciri khas suku } \\
& \text { Oleaceae? }\end{array}$ \\
\hline 2. & $\begin{array}{l}\text { Hubungan } \\
\text { kekerabatan jenis } \\
\text { pohon }\end{array}$ & 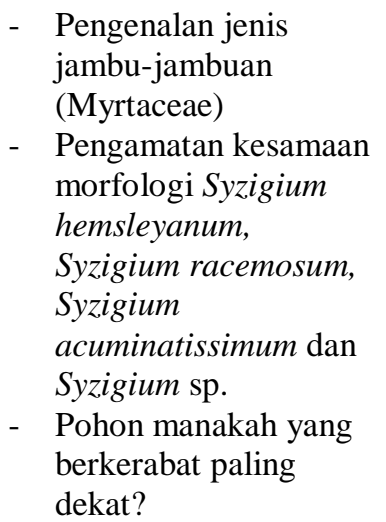 \\
\hline 3. & $\begin{array}{l}\text { Pengenalan marga } \\
\text { Ficus (beringin) }\end{array}$ & 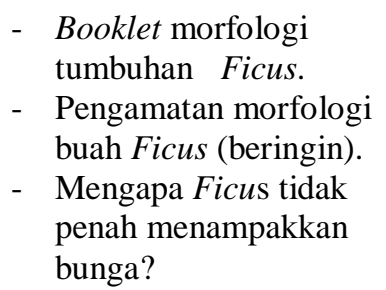 \\
\hline 4. & Identifikasi pohon & $\begin{array}{ll}\text { - } & \text { Kunci determinasi } \\
\text { - } & \text { Buku begambar } \\
\text { pengenalan pohon } \\
\text { - } \\
\text { Tentukan nama } \\
\text { ilmiah pohon (tidak }\end{array}$ \\
\hline
\end{tabular}

berlabel) yang menjadi pilihanmu! Apa nama maga, jenis dan suku pohon tersebut?

Program interpretasi pada Tabel 2 menunjukkan beberapa istilah teknis yang harus dikuasai peserta pelatihan. Agar dapat menerapkan program ini dengan baik, telah disiapkan kunci determinasi, booklet dan deskripsi morfologi pohon. Pada saat sosialisasi, tim pengabdian telah mendemonstrasikan cara penggunaan kunci determinasi sampai menemukan nama jenis tumbuhan yang diidentifikasi. Kesulitan yang dihadapi peserta dalam penggunaan kunci determinasi karena banyak istilah morfologi tumbuhan. Kendala ini dapat diatasi tim pengabdian dengan menjelaskan istilah morfologi berdasarkan spesimen asli tumbuhannya. Berkat pengamatan yang terus menerus, peserta pelatihan semakin familiar dengan istilah morfologi. Untuk memudahkan pengenalan flora oleh pelajar, istilah morfologi yang ada dalam booklet dan deskripsi juga telah disederhanakan dan dilengkapi ilustrasi gambar skematis.

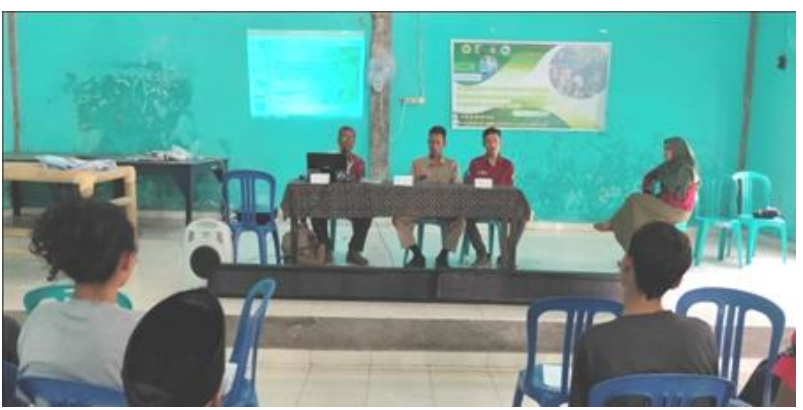

Gambar 1. Sosialisasi Interpretasi Flora Jalur Pendakian Propok, Lombok Timur.

Penggunaan bahasa latin untuk namanama flora pohon umumnya mudah diucapkan peserta pelatihan, walaupun masih ada beberapa peserta yang masih kesulitan. Peserta yang merasa kesulitan diatasi dengan cara menunjukkan foto-foto pohon tersebut yang dilengkapi bahasa lokal dan pemanfaatannya. Selain itu, melalui penugasaan menuliskan dan melafalkan nama latin ini, peserta tersebut 
menjadi mudah mengingat dan menjadi bersemangat.

\section{Pendampingan Praktek Interpretasi Flora}

Peserta pelatihan melakukan kegiatan praktek interpretasi flora berdasarkan panduan yang telah disiapkan. Sebelum melakukan praktek, peserta wajib membaca jalur interpetasi untuk menemukan jenis-jenis flora pohon yang menjadi objek interpretasi. Materi interpretasi yang disampaikan berdasarkan program yang telah disusun (Tabel 2). Pada saat praktek dilakukan, para peserta didampingi tim pengabdian dalam kegiatan intepretasi. Peran tim pengabdian dalam pendampingan adalah untuk mengarahkan dan memandu peserta pelatihan.

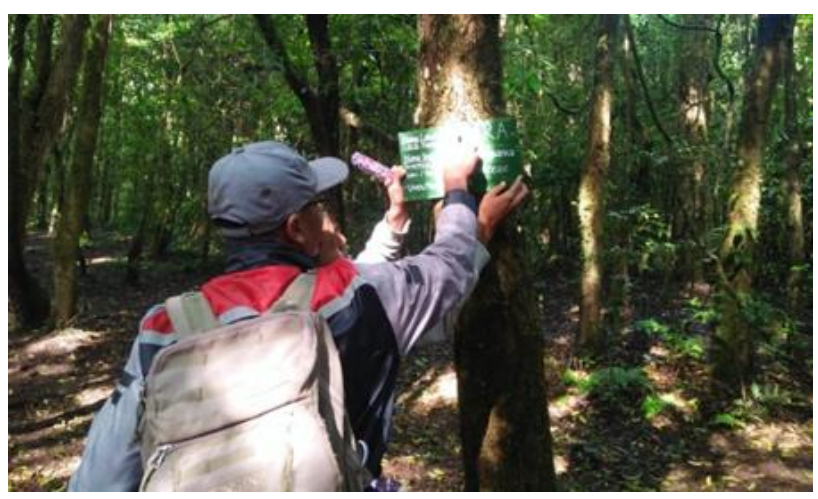

Gambar 2 Pendampingan Praktek Interpretasi Flora Pohon oleh Tim Pengabdian

Praktek interpretasi flora pohon yang didampingi tim pengabdian disambut positif oleh peserta pelatihan. Peserta pelatihan sangat antusias dalam menyampaikan materi interpretasi. Peserta ingin terus melanjutkan interpretasi setelah selesai pada satu pohon untuk mencoba pada pohon yang lain. Tim pengabdian memantau kegiatan interpretasi dan memberikan masukan perbaikan jika ada kekeliruan yang dilakukan peserta.

Hasil pengamatan yang dilakukan tim pengabdian menunjukkan bahwa pada dasarnya pelaksanaan interpretasi flora yang dilakukan peserta pelatihan berjalan sesuai panduan yang diberikan dan berjalan lancar. Walaupun demikian, masih perlu penyempurnaan pada skenario cerita. Agar dapat menjalankan skenario cerita dengan baik, interpreter sebaiknya menggali pula potensi diluar objek interpretasi sehingga penjelasan menjadi lebih komprehensip.

Dalam kegiatan praktek terbimbing pengenalan jenis, peserta pelatihan telah melakukan identifikasi pohon menggunakan kunci determinasi dan booklet. Hasil penugasan identifikasi di lapangan menunjukkan sekitar $76 \%$ peserta pelatihan telah berhasil menentukan dengan benar jenis yang diidentifikasi.

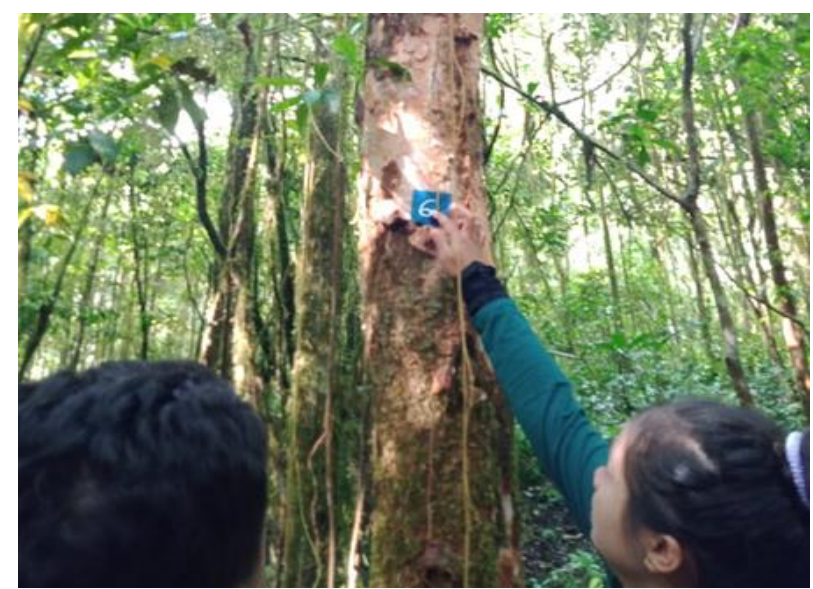

Gambar 3. Penentuan pohon yang akan diidentifikasi

Keberhasilan identifikasi flora pohon oleh peserta pelatihan ada hubungannya dengan kesiapan media identifikasi. Ilustrasi gambar skematis yang ditampilan untuk mempertegas peristilahan morfologi tumbuhan sangat membantu pemahaman peserta. Demikian pula tampilan foto-foto pohon yang jelas dalam booklet membantu menguatkan hasil identifikasi.

\section{Praktek Mandiri Interpretasi Flora}

Praktek mandiri intepretasi flora dilakukan setelah persiapan peserta dianggap cukup dalam waktu tertentu. Praktek mandiri yang dimaksud disini adalah praktek tanpa bimbingan tim pengabdian. Sebelum dilakukan praktek mandiri interpretasi flora, para peserta diberi kesempatan selama tiga hari untuk mempelajari materi dan menyiapkan skenario 
cerita dengan menggali sebanyak-banyaknya informasi yang berhubungan dengan objek interpretasi.

Hasil pemantauan di lapangan menunjukkan bahwa setelah diberi tugas mendalami objek interpretasi (flora pohon), kemajuan kegiatan interpretasi flora yang dilakukan peserta mengalami peningkatan cukup tinggi, yakni mencapai $98 \%$.

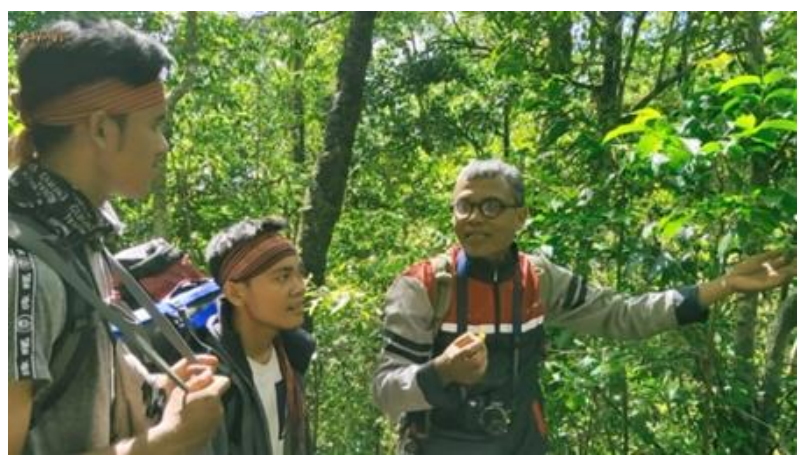

Gambar 4. Wawancara hasil kegiatan interpretasi flora terhadap pelajar yang berkunjung di kawasan Propok.

Dalam kegiatan praktek mandiri, beberapa peserta melakukan uji coba interpretasi flora yang disajikan kepada pelajar yang berlibur di kawasan Propok, dan mendapat sambutan positif. Hasil wawancara terhadap pengunjung setempat terkait kegiatan wisata edukasi interpretasi flora ini, diperoleh hasil bahwa kegiatan ini sangat bermanfaat karena sambil berwisata mereka mendapat pengalaman berharga yang banyak berhubungan dengan pelajaran keanekaragam hayati di sekolah. Dengan demikian wisata sambil belajar sangat menyenangkan sehingga dapat menambah daya tarik wisata di kawasan Propok.

\section{Kesimpulan}

Berdasarkan hasil sosialisasi dan praktek inteperpretasi dapat ditarik kesimpulan: (1) Pelatihan interpetasi flora mendapat respon positif dari peserta pelatihan dan merupakan pengalaman sangat berharga untuk meningkatkan keterampilan dalam kegiatan wisata edukasi, (2) Antusias yang besar dari peserta pelatihan dalam melaksanakan praktik interpretasi flora sangat menunjang keberhasilan kegiatan pelatihan ini, dan (3) Kegiatan interpretasi flora pohon terhadap pelajar di jalur pendakian Propok mendapat sambutan baik, dinilai sangat bermanfaat dan menyenangkan.

\section{Ucapan Terima Kasih}

Terima kasih kepada LPPM UNW Mataram yang telah memberikan dukungan finansial dan kepada Yayasan Baitul Maal (YBM) PLN yang telah memberi dukungan material terhadap terlaksananya kegiatan pengabdian kepada masyarakat ini. Terimakasih disampaikan juga kepada Taman Nasional Gunung Rinjani (TNGR) yang telah memberikan kesempatan dalam pelaksanaan pengabdian ini.

\section{Daftar Pustaka}

Endriesta, N. P. 2019. Pengembangan Media Interpretasi Non Personal Sebagai Upaya Mendukung Wisata Edukasi Di Obyek Wisata Taman Balekambang Kota Suakarta. Sekolah Tinggi Pariwisata Sahid Surakarta.

Eva, R. 2011. Interpretasi. Institut Pertanian Bogor. www.vea.staff.ipb.ac.id/files/2011/02/I nterpretasi-JICA.doc, diakses tanggal 15 September 2021.

Mertha, I Gde., H. Rizkiawan, A. Satriadi, P.S. Waskito. 2020. Sosialisasi Penangulangan Sampah Melalui Pendekatan Zero Waste. Jurnal Pengabdian Pendidikan IPA (3)1: 4348 